\title{
Shear Strength Enhancement of Cemented Reinforced Sand: Role of Cement Content on the Macro-Mechanical Behavior
}

https://doi.org/10.2478/sgem-2019-0020

received January 22, 2019; accepted July 6, 2019.

\begin{abstract}
Sands reinforced by hydraulic binders (cement) have constituted in recent decades a major asset for the expansion of several areas of engineering. The mechanical behavior of sand-cement mixtures has undergone some controversies studied on the Chlef sand. In this paper, we present an experimental study to investigate the mechanical behavior of a sandy soil reinforced by a hydraulic binder (cement), using the direct shear apparatus emphasizing on the shear strength characteristics and the vertical deformation variation of cemented reinforced sand. The parameters used in this study are mainly: relative density $(\mathrm{Dr}=80 \%)$, normal stress ( $\sigma \mathrm{n}=100,200,400 \mathrm{kPa})$, water content $(3,7$ and $10 \%)$, cement content $(2.5,5,7.5$ and $10 \%)$ and cure time (7, 14 and 28 days). The experimental results show that the mechanical characteristics in terms of internal cohesion (C) and internal frication angle $(\varphi)$ give a better mechanical performance with the binder inclusion, and the cure conditions play an effective role on the improvement of the shear strength. This result also showed that $10 \%$ of the cement content gave us a maximum value of shear strength and an optimal influence on the mechanical characteristics. The addition of cement not only improves the shear strength of soil, but also provides diversity in the resistance against the deformations imposed load, which can be established by a dilatant character.
\end{abstract}

Keywords: Cemented reinforced sand; direct shear test; water content; curing time; dilatant character.

\footnotetext{
*Corresponding author: Ismail Benessalah, LsmE Laboratory of Materials Sciences and Environment, Univ. UHBC Hassiba Benbouali of Chlef, 02091 Chlef, Algeria, E-mail: i.benessalah@univ-chlef.dz Kheira Boutouba, Ahmed Arab, LsmE Laboratory of Materials Sciences and Environment, Univ. UHBC Hassiba Benbouali of Chlef, 02091 Chlef, Algeria

Kheira Boutouba, Ahmed Djafar Henni, Laboratory of Structures, Geotechnics and Risks, University Hassiba Benbouali of Chlef, Algeria
}

\section{List of symbols}

$\begin{array}{ll}\varphi & \text { Internal friction angle } \\ C & \text { Interlocking or intercept cohesion } \\ D r & \text { Relative density } \\ D 50 & \text { Mean grain size } \\ \delta H & \text { Horizontal displacement } \\ \delta V & \text { Vertical displacement } \\ \text { Cunif } & \text { Uniformity coefficient } \\ C_{\text {curv }} & \text { Coefficient of curvature } \\ \text { emax } & \text { Maximum void ratio } \\ \text { emin } & \text { Minimum void ratio } \\ e & \text { Global void ratio } \\ \gamma s & \text { Specific weight of solids } \\ \sigma n & \text { Normal stress } \\ \tau & \text { Shear strength } \\ \tau m a x & \text { Peak shear strength } \\ S E M & \text { Scanning electron microscope } \\ C C & \text { Cement content } \\ G s & \text { Specific gravity of sand } \\ G f & \text { Specific gravity of silt } \\ D 10 & \text { Sand effective grain size } \\ \text { Ip } & \text { Plasticity index } \\ I B & \text { Brittleness index } \\ \omega, w & \text { Water content }\end{array}$

\section{Introduction}

The reinforcement of soil in place remains an important activity area in the field of geotechnical engineering. It aims to improve the mechanical qualities of soil by increasing its resistance, reducing its permeability and controlling its deformability. Several methods are used in this area including the methods involving the use of planar or continuous inclusions (e.g., metal strips, geogrids, geotextiles) within earthen structures. Plans of weakness can be introduced along the interface between the reinforcement and the ground because the shear 
strength of the interface is generally greater than that of the ground. And other possibilities are conceivable such as the traditional methods: densification, treatment with hydraulic binders (cement, lime, etc.) and the incorporation into the ground reinforcement structures. The interest is then to find reliable, safe, inexpensive and quick to implement solutions.

The technique of reinforcing poor quality soil by cement is more and more necessary, given the growth of humanity and its activities. Certain types of soil, hitherto neglected because they have weak mechanical characteristics, must be reinforced to ensure the stability of buildings and civil engineering infrastructures. The method of including a hydraulic binder to improve the mechanical characteristics of soils is to homogeneously mix the cement in the soil with certain water content and play the role of reinforcement locally.

Several researchers have demonstrated the effectiveness of adding cement to the mechanical behavior of soils (such as Coop et al, 1993; Consoli et al., 1998; Schnaid et al., 2001; Asghari et al., 2003; Haeri et al., 2006; Sharma et al., 2011; Baxter et al., 2011; Heathcote et, 1994). They showed that cemented sands show brittle behavior with an apparent peak in the stress-strain curve. Increasing the cement content increases the shear strength and the expansion rate. Venkatarama et al. (2005) studied the characteristics of blocs of cemented soil using mixtures of very sandy soils. The cement content of the block is varied by keeping the soil mixing and block density constant, they found that the compressive, flexural and direct tensile strength of the soil-cement blocks increased by about 2.5 times for a cement content of 6\%. Maher and Ho. (1993) conducted static and dynamic triaxial compression and extension tests on cemented sand containing randomly distributed fibers and reported more shear strength and energy absorption for soil containing fiber. A study of DOS Santos et al. (2010), whose experiments reported on fiber-reinforced cemented sand under pressures up to $40 \mathrm{MPa}$, reported that the fiber-reinforcement reduced fracture propagation and cracks in the cemented sand particles. Improved mechanical properties of soils due to fiber reinforcement cannot be a general rule to destroy, and due to this, contradictory conclusions of the majority of researchers can be explained by the kind and the shape of the fibers used or the physical characteristics of the soil, their relative density and the method of samples preparation. Mateus et al. (2016) presented an analysis carried out from the axial compression of the mixture between sand and Portland cement and water, the composition was prepared with $3 \%$ and $7 \%$ cement and $10 \%$ water content for five different curing times, the results show that the higher percentage of cement has generated low void levels, which consequently increases the resistance. Experimental data obtained from the drained triaxial compression tests on cemented sand by Marri et al. (2010) indicate the importance of the degree of cementation and the confining pressure on the stress-strain behavior of the cemented sand. However, the influence of cementation is greater at low confining pressures and decreases with increasing confining pressures that made the effect of this parameter becomes dominant. In addition, scanning electron microscope SEM analysis of cemented samples revealed that stress level and cement content affect particle breakage. New requirements concerning the method and the material have been accumulated: increase in strength, rigidity, impermeability, homogeneity, durability, prediction of the resistance according to the type of soil, and so on. Numerous studies on the dry method as well as some on the wet method provide some answers (Consoli et al., 2009, 2010, 2011; Lee et al., 2010; Shahnazari et al., 2013 ; Hirabayashi et al ., 2009 ; Kido et al., 2009 ; Umesha et al., 2009). However, there is no global parametric study studying both the impact of soil type and quantity of water on the characterization of cemented soil material. In the same way, the workability of the material has not yet been studied. The influence of the sandy part as well as that of the grain size on the ground, are also some of the most relevant questions.

The objective of our research project is, therefore, to improve the dosing methods as well as the sizing methods of the structures in cemented soil. In the same way, the determination of the field of workability of the material for use in wet method is capital for its homogeneity and the continuity of the works, and thereby performing a parametric study on the cemented soil material. A series of direct shear tests were carried out on a sandy soil reinforced by a hydraulic binder (cement). The use of the direct shear apparatus enabled us to study the characteristics of the shear strength and the variation of vertical deformation of cemented sand. The parameters used in this study are mainly: the relative density $(\mathrm{Dr}=$ $80 \%$ ), the normal stress ( $\sigma n=100,200$ and $400 \mathrm{kPa}$ ), the water content $(\omega=3,7$ and $10 \%)$, cement content $(C c=$ 2.5, 5, 7.5 and 10\%) and curing time (7, 14 and 28 days). 
Table 1: Physical characteristics of Chlef sand and cemented sand.

\begin{tabular}{|c|c|c|c|c|c|c|c|}
\hline Materials & Cc (\%) & $Y_{s}\left(\mathrm{~g} / \mathrm{cm}^{3}\right)$ & $\mathrm{D}_{50}(\mathrm{~mm})$ & $C_{\text {unif }}()$. & $C_{\text {curv }}()$. & $\mathbf{e}_{\min }()$. & $e_{\max }()$. \\
\hline Sand & 0 & 2.719 & 0.44 & 2.35 & 1.32 & 0.588 & 0.853 \\
\hline \multirow[t]{4}{*}{ sand cemented } & 2.5 & 2.735 & 0.43 & 2.5 & 1.4 & 0.542 & 0.831 \\
\hline & 5 & 2.765 & 0.42 & 2.66 & 1.5 & 0.535 & 0.811 \\
\hline & 7.5 & 2.81 & 0.41 & 2.75 & 1.45 & 0.529 & 0.815 \\
\hline & 10 & 2.845 & 0.4 & 2.85 & 1.5 & 0.517 & 0.823 \\
\hline
\end{tabular}

\section{Experimental program}

\subsection{Materials}

A series of direct shear tests were carried out on the sandy soil of the Chlef area, from the banks of the Chlef Valley. The soil was initially air dried and sieved through a $2 \mathrm{~mm}$ sieve, Fig. 3(a). Chlef sand particles are with a reduced grain shape and quartz with some carbonates, and they are usually isometric particles. Figure 1 shows a microscopic view of an electronic scanning of the tested sand. The basic properties of sand are given in Table 1, the grain size distribution curves of this soil with different cement content are shown in Figure 2. Many researches were performed to study the Chlef sand behavior (Arab et al., 2008, 2009, 2014; Djafar et al., 2011, Belkhatir et al., 2013; Benessalah et al. 2019 ; 2018 ; 2017 ; 2016 ; Della et al. 2011; Aouali et al., 2018; Merabet et al. 2019).

The cement used in this study is the cement of Chlef CEM II/A type of 42.5 classes, density 3.1 and a surface area of $3298 \mathrm{~cm}^{2} / \mathrm{g}$. The silica fume used in cement is $8 \%$, according to the standard EN 13263-1, having a density of 2.4 and a surface area of $220000 \mathrm{~cm}^{2} / \mathrm{g}$ (Figure 3(b)). The chemical and mineralogical characteristics of the cement smoke are shown in Table 2. The mixture of soil and cement is introduced into a kneader for 2 minutes while adding appropriate water content.

\subsection{Samples preparation and tests procedures}

A series of 117 tests was carried out in a rectangular shear box to study the effect of adding cement on the shear strength of the cemented sand. The shear box had a dimension of $60 \times 60 \mathrm{~mm}$ horizontal cross section; the height of the test piece was $25 \mathrm{~mm}$. All tests were performed according to the standard ASTM D-3080 (2005)

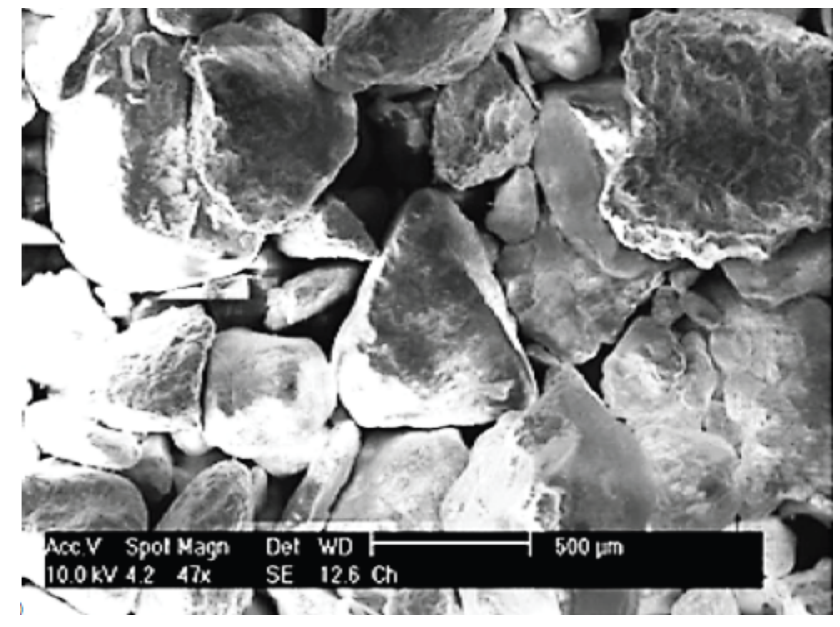

Figure 1: Scanning electron microscope view (SEM) of Chlef sand, Della et al. (2014).

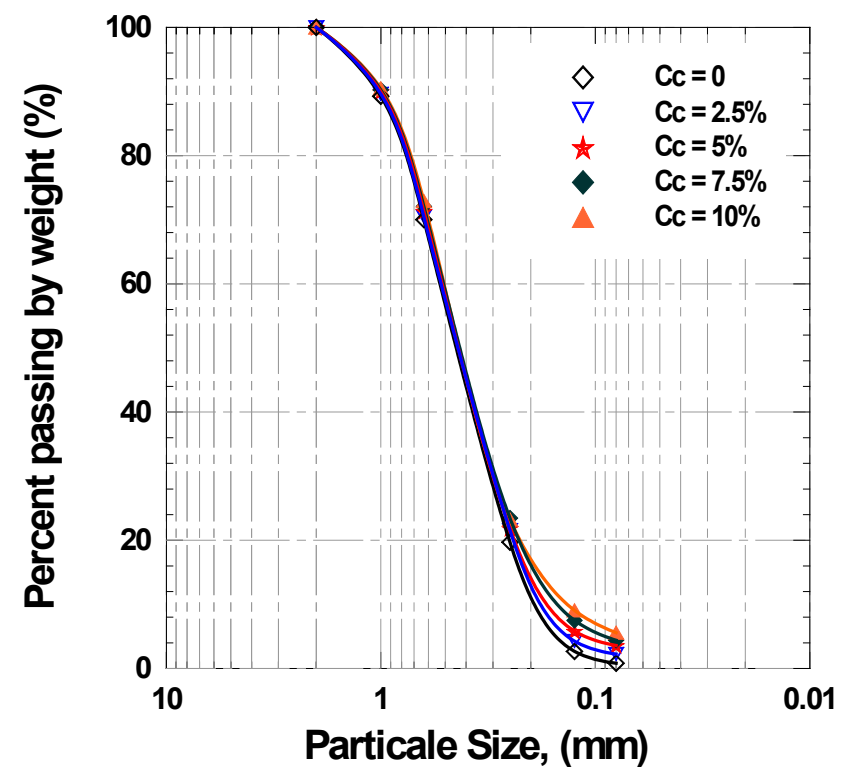

Figure 2: Grain size distribution curve of Chlef sand and cemented sand. 

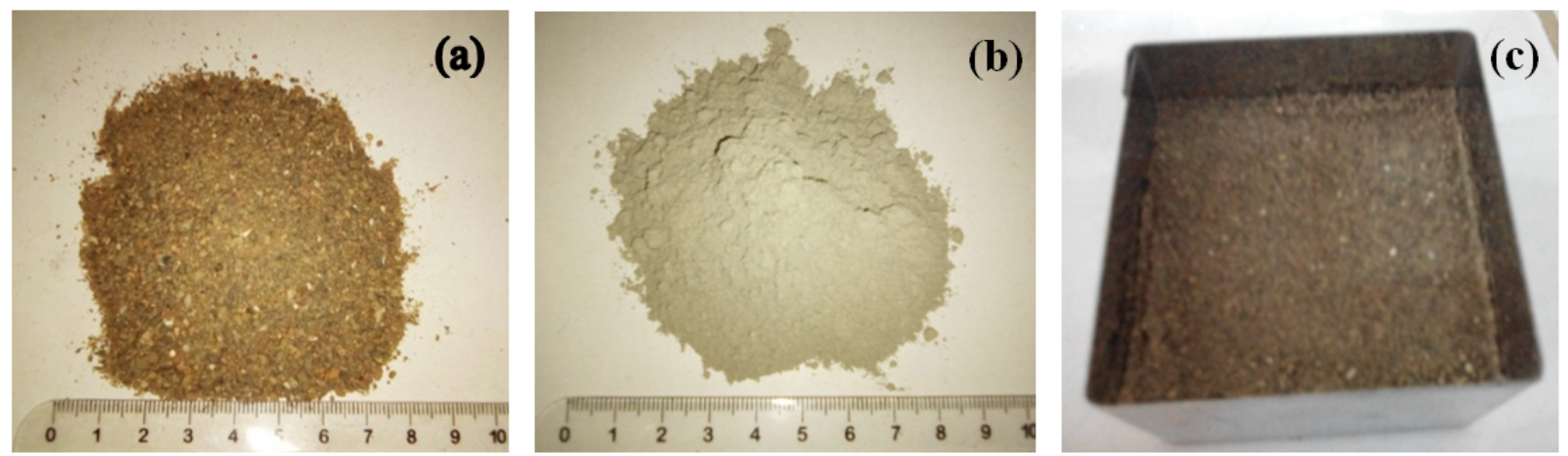

Figure 3: Materials used in this study: (a) Sand, (b) Cement, (c) Sample preparation.

Shear stress was recorded as a function of horizontal displacement to an average shear strain of $13 \%$.

The first series in this laboratory study concerned shear tests on unreinforced Chlef sand with different water contents $\omega=3,7$ and $10 \%$, the second series carried out involved 108 tests on a mixture of sand-cement with a cement content $C c=2.5,5,7.5$ and $10 \%$. The dense relative density ( $D r$ ) used was $80 \%$. Samples were sheared under normal stresses $s n=100,200$ and $400 \mathrm{kPa}$. The sample preparation time was approximately one hour for setting the cement; then they are placed in a room at a temperature of $26^{\circ} \pm 2$ for a duration of 7,14 and 28 days with a humidity of $90 \%$. The average cement concentration is defined as a percentage of the dry weight of sand, according to the following equation:

$$
C_{C}=\frac{W_{C}}{W_{S}} \times 100[\%]
$$

With: Wc the cement weight and Ws the sand weight.

Each sample was prepared in three layers (Figure 3(c)). The mass of each layer was determined according to the value of the initial relative density $(D r)$. Each layer was poured into the mold and then compacted manually; the number of strokes was 25 until obtaining the desired height for the dense tests. Table 3 shows all the parameters considered in the test program.

\section{Results and discussion}

\subsection{Unreinforced sand}

Figure 4(a) illustrates the results of the shear box tests on the unreinforced sand samples with water contents of 3 ,
Table 2: Chemical and mineralogical compositions of the cement.

\begin{tabular}{llll}
\hline \multicolumn{3}{l}{ CEM II/A } \\
\hline \multicolumn{2}{l}{ Chemical compositions (\%) } & \multicolumn{2}{l}{ Mineralogical compositions (\%) } \\
\hline $\mathrm{SiO}_{2}$ & 20.58 & $\mathrm{C}_{3} \mathrm{~S}$ & 57.79 \\
$\mathrm{Al}_{2} \mathrm{O}_{3}$ & 4.90 & $\mathrm{C}_{2} \mathrm{~S}$ & 20.47 \\
$\mathrm{Fe}_{2} \mathrm{O}_{3}$ & 4.70 & $\mathrm{C}_{3} \mathrm{~A}$ & 7.20 \\
$\mathrm{CaO}$ & 62.8 & $\mathrm{C}_{4} \mathrm{AF}$ & 11.49 \\
$\mathrm{SO}_{3}$ & 2.28 & & \\
$\mathrm{MgO}$ & 0.53 & & \\
$\mathrm{~K}_{2} \mathrm{O}$ & 0.42 & & \\
$\mathrm{Na}_{2} \mathrm{O}$ & 0.12 & \\
$\mathrm{Free}$ lime & 2.17 & \\
\hline
\end{tabular}

7 and 10\%, relative density $\mathrm{Dr}=80 \%$ and sheared under a normal stress of $100 \mathrm{kPa}$. The results clearly show that an increase in water content has a significant impact on the soil shear strength. Soil resistance decreases with increasing moisture content. Figure 4(b) illustrates the variation of the vertical displacement as a function of the horizontal displacement. It is noted here that an increase in the water content leads to an increase in the vertical displacement, and therefore, the contractiveness of the sample increases, these results are consistent with those found by Benessalah et al. (2015).

\subsection{Shear response of the cemented sand samples}

Several researchers (Eathcote et al. 1994; Walker et al. 1995; Huang et al, 1998; Schnaid et al, 2001) showed the contribution of cement content in the evolution of soil resistance. Figure 5 illustrates the results of the direct shear 
Table 3: Parameters of the experimental program.

\begin{tabular}{|c|c|c|c|c|c|c|}
\hline Type of Samples & $\begin{array}{l}\text { Vertical stress } \\
(\mathrm{kPa})\end{array}$ & $\begin{array}{l}\text { Water content } \\
\text { (\%) }\end{array}$ & Cement content (\%) & Relative density (\%) & $\begin{array}{l}\text { Time of cure } \\
\text { (days) }\end{array}$ & Number of tests \\
\hline $\begin{array}{l}\text { Uncemented } \\
\text { samples }\end{array}$ & $\begin{array}{l}100 \\
200 \\
400\end{array}$ & $\begin{array}{l}3 \\
7 \\
10\end{array}$ & 0 & 80 & 0 & 9 \\
\hline Cemented samples & $\begin{array}{l}100 \\
200 \\
400\end{array}$ & $\begin{array}{l}3 \\
7 \\
10\end{array}$ & $\begin{array}{l}2.5 \\
5 \\
7.5 \\
10\end{array}$ & 80 & $\begin{array}{l}7 \\
14 \\
28\end{array}$ & 108 \\
\hline
\end{tabular}
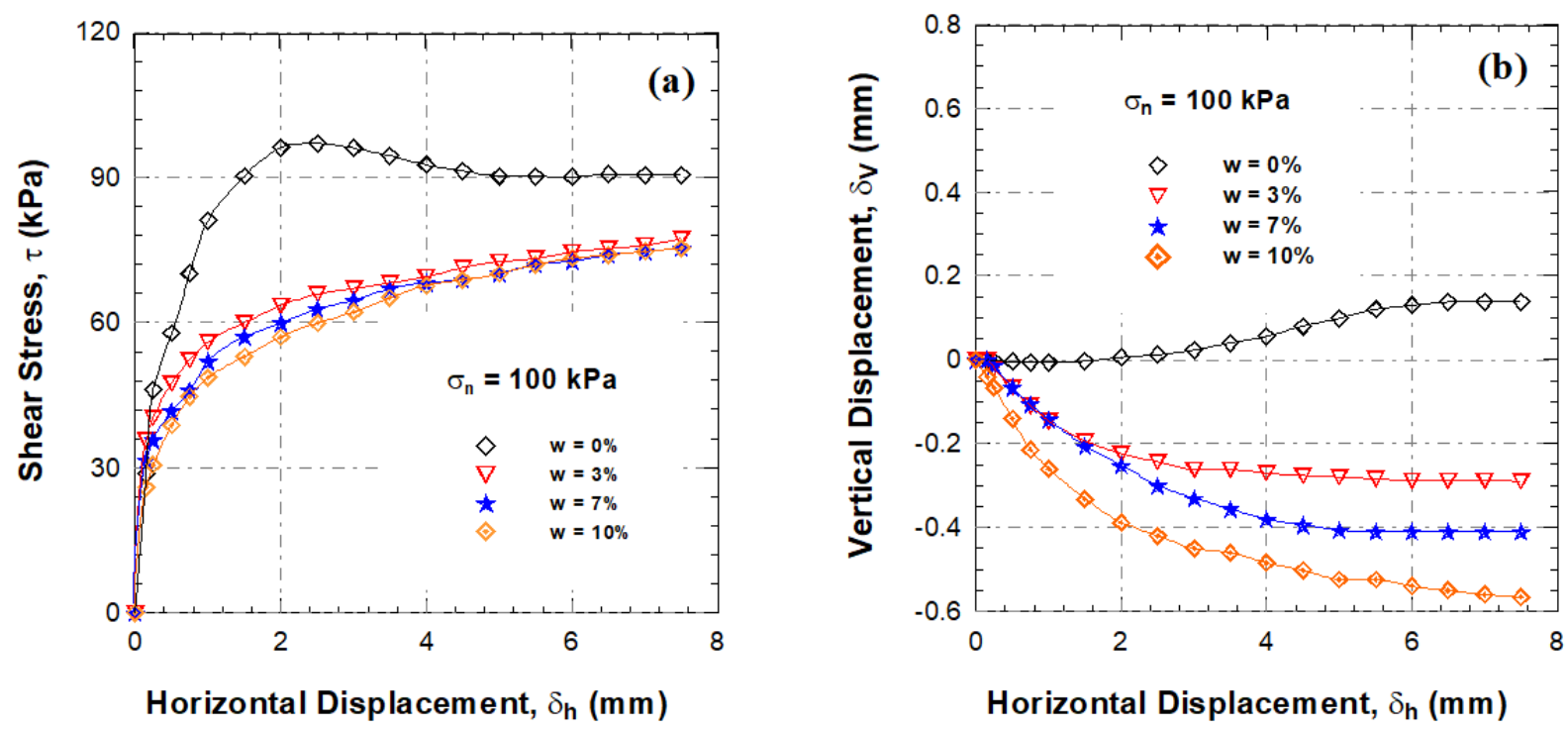

Figure 4: Influence of water content on the behavior of Chlef sand ( $\sigma n=100 \mathrm{kPa}, \mathrm{Dr}=80 \%$ ), (a): Shear stress as a function of horizontal displacement, (b): Vertical displacement as a function of horizontal displacement.

tests on cemented sand samples with a cement content $C c=2.5,5,7.5$ and $10 \%$ with a water content $\omega=3,7$ and $10 \%$ emphasizing with comparison between them and the results of the unreinforced sand. These tests were sheared under a normal stress of $100 \mathrm{kPa}$. The results show that the shear strength of the unreinforced samples increases with increasing horizontal displacement without a peak appearance, while for samples reinforced with cement, it is found that the resistance increases significantly with the increase of the cement content up to a resistance peak of $80,90,100$ and $110 \mathrm{kPa}$ for $C c$ equal to $2.5,5,7.5$ and $10 \%$, respectively; then the resistance drops followed by a residual resistance to the shear end for samples with water content of $3 \%$ (Figure $5(\mathrm{a})$ ). The results of the tests of the samples made with a water content $\omega$ of 7 and $10 \%$ are illustrated in Figures 5(b) and 5(c); a very significant increase in the strength of the mixture is observed with the increase in the cement content where the shear strength reaches values of 106, 181 and 189 for water contents of 3, 7 and $10 \%$ for the samples mixed with $10 \%$ cement. Figures 6(a), 6(b) and 6(c) illustrate the variations of the vertical deformation as a function of the horizontal deformation; the results of these tests show a contractiveness phase for the small horizontal displacements followed by a phase of dilatancy, which reduces the deformability of the grounds against the external forces; on the other hand, the unreinforced sand showed only a contractiveness phase of deformation, which represents the vulnerability of unreinforced sand that will be represented by cracking during external loading.

Figure 7 shows the evolution of the maximum shear strength as a function of the cement content. Note that increasing the normal stress increases the shear strength considerably. It can also be seen that the shear strength of the sand-cement mixture increases with an increase of the cement content according to a quasi-linear growth 

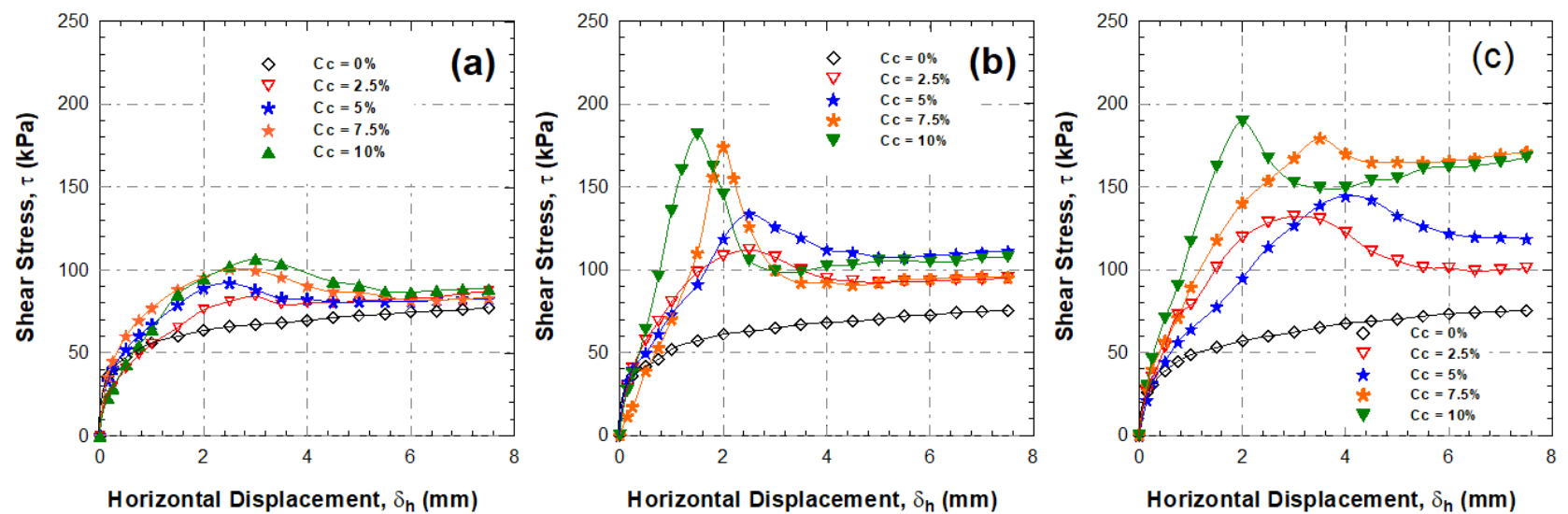

Figure 5: Cement content influence on the shear strength of cemented sand ( $\sigma n=100 \mathrm{kPa}$ ), (a) $\omega=3 \%$, (b) $\omega=7 \%$, (c) $\omega=10 \%$.
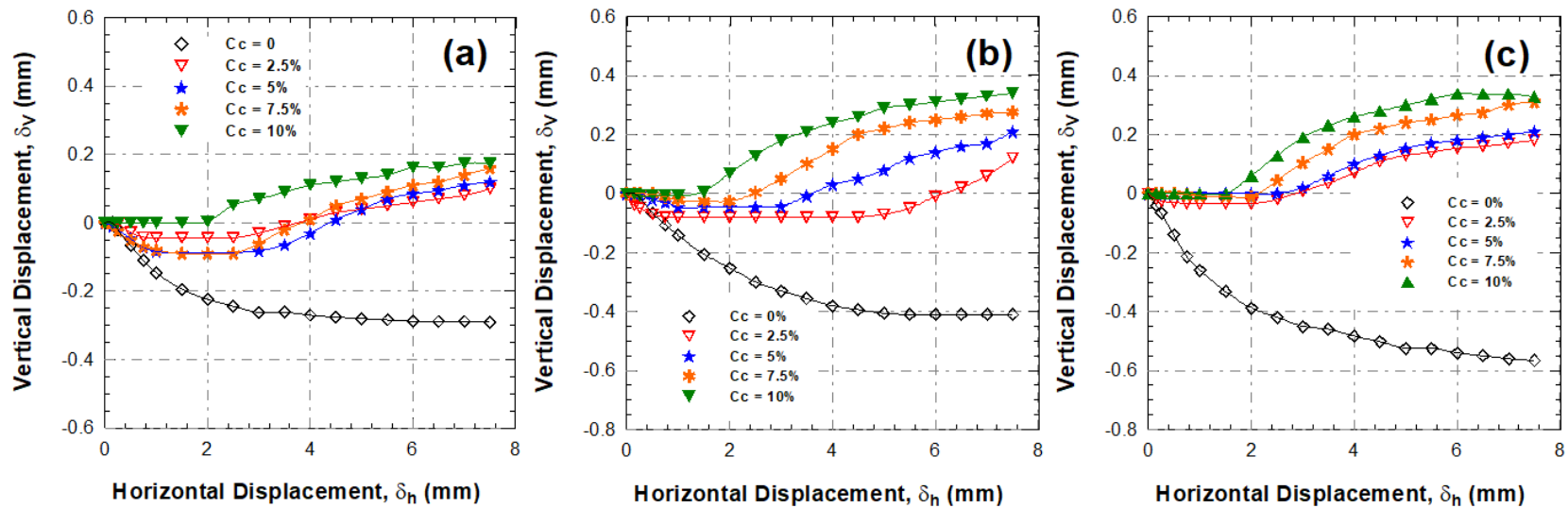

Figure 6: Cement content influence on the vertical displacement of cemented sand ( $\sigma n=100 \mathrm{kPa}),(\mathrm{a}) \omega=3 \%$, (b) $\omega=7 \%,(\mathrm{c}) \omega=10 \%$.

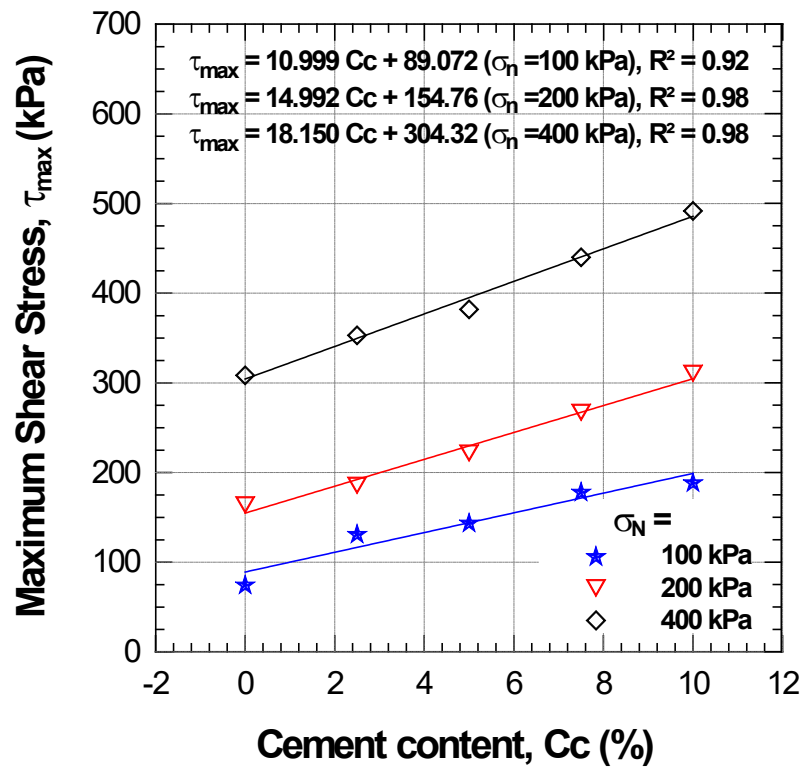

Figure 7: Evolution of the maximum shear strength of cemented reinforced sand as function of cement content (case of a water content $\omega=10 \%)$. (coefficient of determination $R^{2}=0.92,0.98$ and 0.98 for the three normal stresses $\sigma n=100,200$ and $400 \mathrm{kPa}$, respectively).

\subsection{Cement content effect on the mechanical characteristics}

Although a curved rupture envelope is expected for the sand-cement mixtures under study, by a linear regression between the shear stresses and the normal stresses applied to the samples at a given shear displacement; to determine the shear strength parameters including friction angle and the interlocking between the particles or the intercept cohesion. Variations in internal friction angle and intercept cohesion versus cement content are shown in Figure 8. Here, the interception of cohesion and the friction angle increase as the cement content increases. In particular; Figure 8(a) illustrates the evolution of the interlocking that has been presented in the figure as an intercept cohesion 

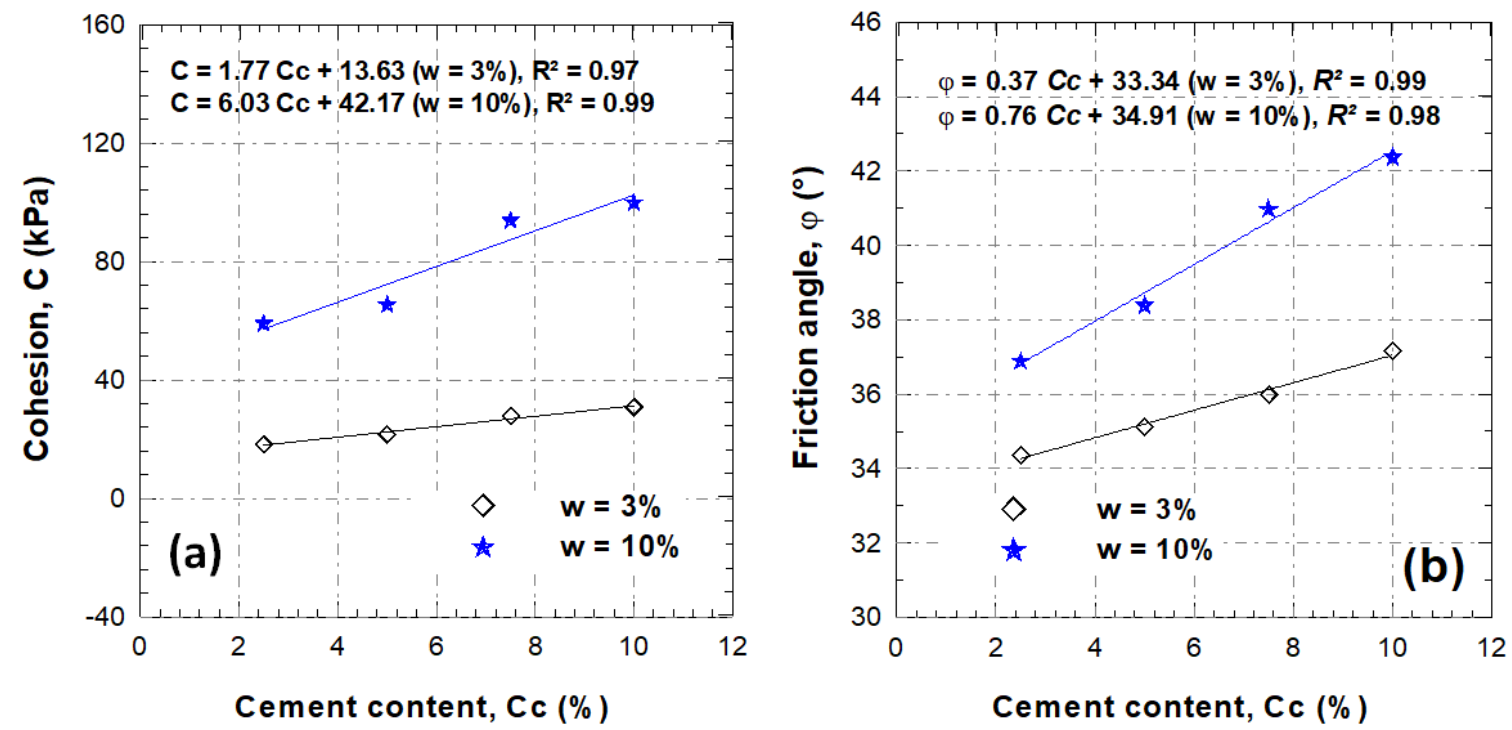

Figure 8: Influence of the cement content on the mechanical properties of cemented sand: (a) variation of the interlocking or intercept cohesion; (b) Variation of the friction angle.

of the mixture versus the cement content for water contents $\omega=3$ and $10 \%$. The results clearly show that the intercept cohesion $(C)$ of the soil increases linearly with the increase of the cement content and also with the water content ( $\omega=10 \%$ has greater values of intercept cohesions of all the samples under study, approximately the double of the values obtained with $\omega=3 \%$ ). Figure 8(b) illustrates the evolution of the friction angle with the increase in the cement content $(C c)$; here, we find that the friction angle $(\varphi)$ increases significantly and with a linear manner with an increase in the cement content $(C c)$ for all the mixtures under study. Water content decreases immediately due to cement hydration and long-term pozzolanic reactions as water is absorbed and converted to cement-based products (Bergado et al., 1996, Bennert et al., 2000; Chew et al., 2004). So, the increase in curing time increases the shear strength, and consequently, also increases on the cohesion and the angle of friction because of continuous cementing reactions. Our results are in good agreement with those found by (Consoli et al., 2009; Amini et al., 2013; Asghari et al., 2003). These results show in addition the positive role of the water content in the improvement of the mechanical behavior of cemented reinforced sand and also indicate that the optimum water content is not yet reached taking into account the two values used in this study. Consoli et al. (1998) used the brittleness index as an indicator of the brittle behavior of soil as follows:

$$
I_{B}=\frac{q_{\max }}{q_{\text {res }}}-1
$$

where: $\mathrm{I}_{\mathrm{B}}$ is the brittleness index, and $\mathrm{q}_{\max }$ and $\mathrm{q}_{\mathrm{res}}$ are the peak and residual deviatoric stresses, respectively. They indicated that the addition of cement in the composite material leads to an increase in stiffness, brittleness and peak resistance. However, they noted that the inclusion of fibers increases both the peak and residual triaxial strength and reduces stiffness, which makes it possible to change the brittle behavior to a more ductile one.

\subsection{Influence of curing time on the shear strength}

It is known that cure temperature plays a very important role in the evolution of resistance; a high temperature of the environment generates a faster development of the resistance against a low temperature will slow down the setting process. Several studies have been developed in this direction, such as Hashimoto et al. (2009), Ahnberg et al. (2003), and Umesha and Val (2009). For temperatures below zero, the process will not be triggered by the freezing of water molecules. Figure 9 illustrates the results of stress-strain shear tests for cement-treated samples that were cured at 7,14 and 28 days. It can be seen from the results that the shear strength increases significantly with increasing curing time, for example, the sample with $10 \%$ cement for a curing time of 7 days, has a resistance of 190 $\mathrm{kPa}$; after 14 days, the resistance increases to $270 \mathrm{kPa}$ and continues to increase to reach the value of $290 \mathrm{kPa}$ after 28 days. This increase in resistance is due to curing time 

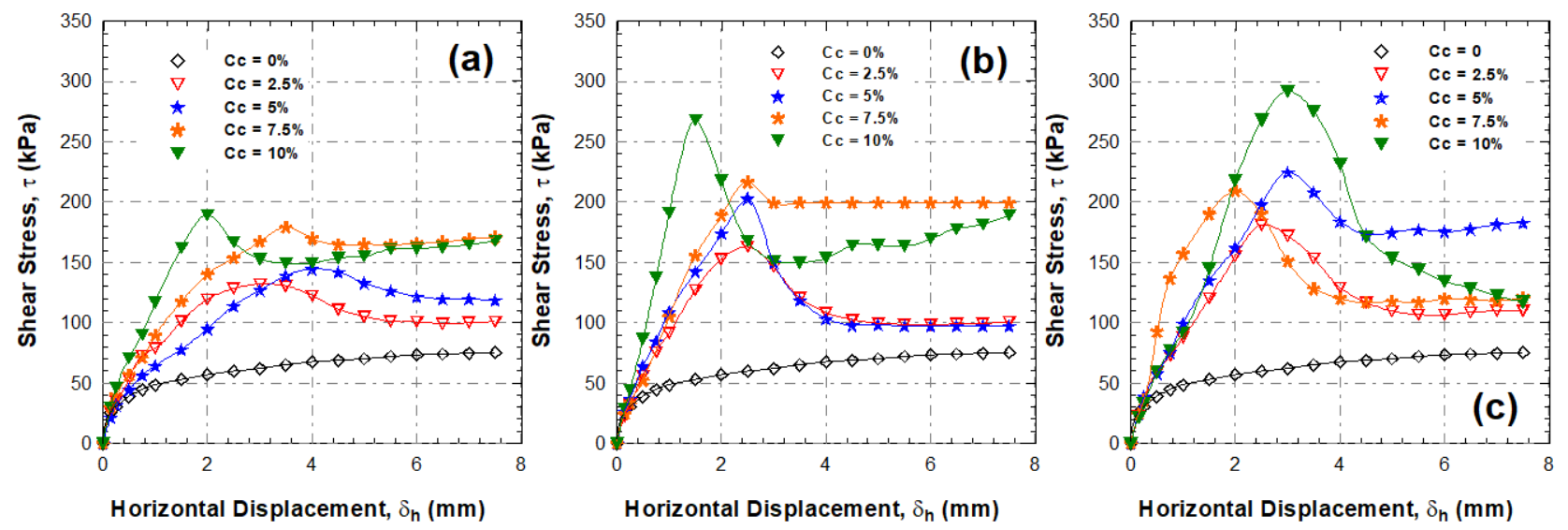

Figure 9: Influence of curing time on shear strength of cemented sand ( $\sigma n=100 \mathrm{kPa}$ ), (a) after 7 days, (b) 14 days, (c) 28 days.
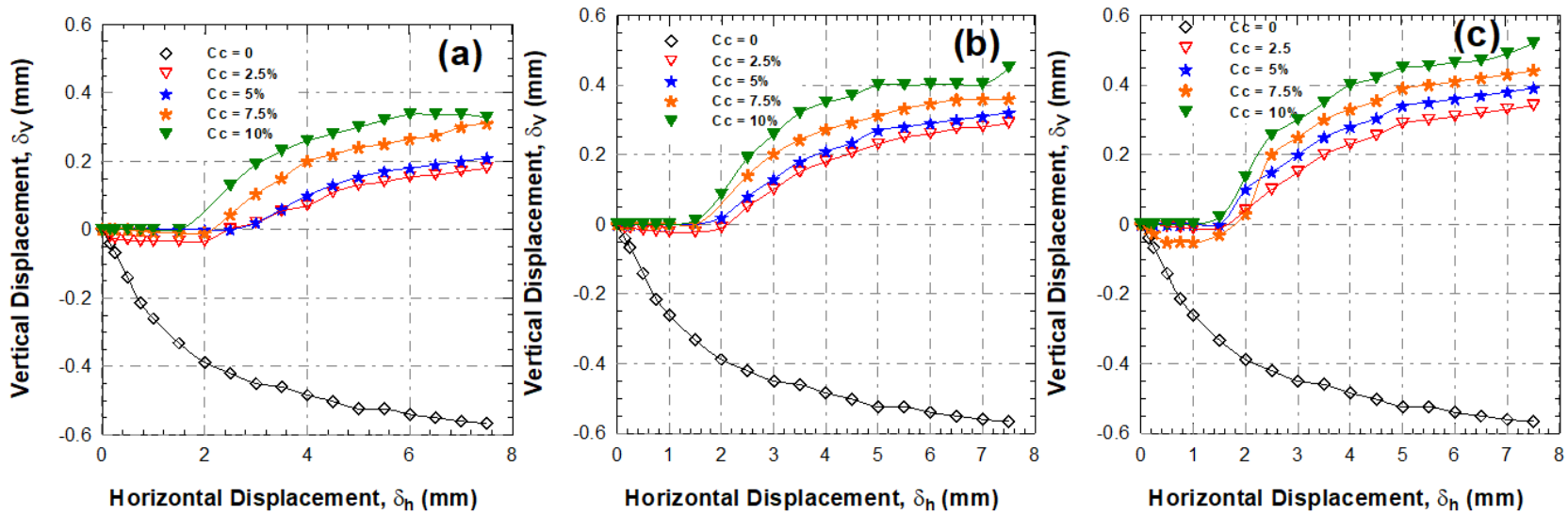

Figure 10: Influence of curing time on deformability of cemented sand ( $\sigma n=100 \mathrm{kPa}$ ), (a) after 7 days, (b) 14 days, (c) 28 days.

on increasing the rigidity of the soil. Figure 10 illustrates the evolution of vertical deformations as the functions of horizontal deformations. It is noted that the increase in the cement content and the cure time considerably reduces the deformability of the mixtures that is represented by reducing the contractiveness character, and having a dilatant character after around $2 \mathrm{~mm}$ of horizontal displacement. These results are in perfect agreement with those found by Zillur Rabbi et al. (2011).

Figure 11 shows the evolution of maximum shear strength as a function of cement content and curing time. The results of the samples show that maximum shear strength increases almost linearly with increasing cement content and also with increasing cure time. These results are attributed to the interaction and also to the cement bonding of the sand particles, and consequently, the resistance and the improvement of the mechanical behavior increases. These results are close concordances with those found by Consoli et al. (1998) and Schnaid et al. (2001).
The intercept cohesion values obtained with deferent cement content for the three curing times namely 7, 14 and 28 days for the samples of high relative density $(D r=80 \%)$, are presented in Figure 12a. It is noted that the intercept cohesion $(C)$ increases very significantly with the increase in cement content according to almost linear growth $\left(R^{2}=0.952, R^{2}=0.918, R^{2}=0.882\right.$, for 7, 14 and 28 days, respectively). It is also noted that shear strength increases with an increasing curing time. Figure 12(b) illustrates the evolution of the angle of friction as a function of the cement content. The results clearly show that the angle of internal friction also increases linearly with an increase in the cement content and also with an increase in curing time $\left(R^{2}=0.986, R^{2}=0.934, R^{2}=0.874\right.$, for 7,14 and 28 days).

Table 4 illustrates a summary of our results with those found in the literature, particularly those of Amini et al. (2013), Asghari et al. (2003) and Consoli et al. (2009). Comparing our results with those of Amini et al., (2013), we find that the addition of cement in the sand is 

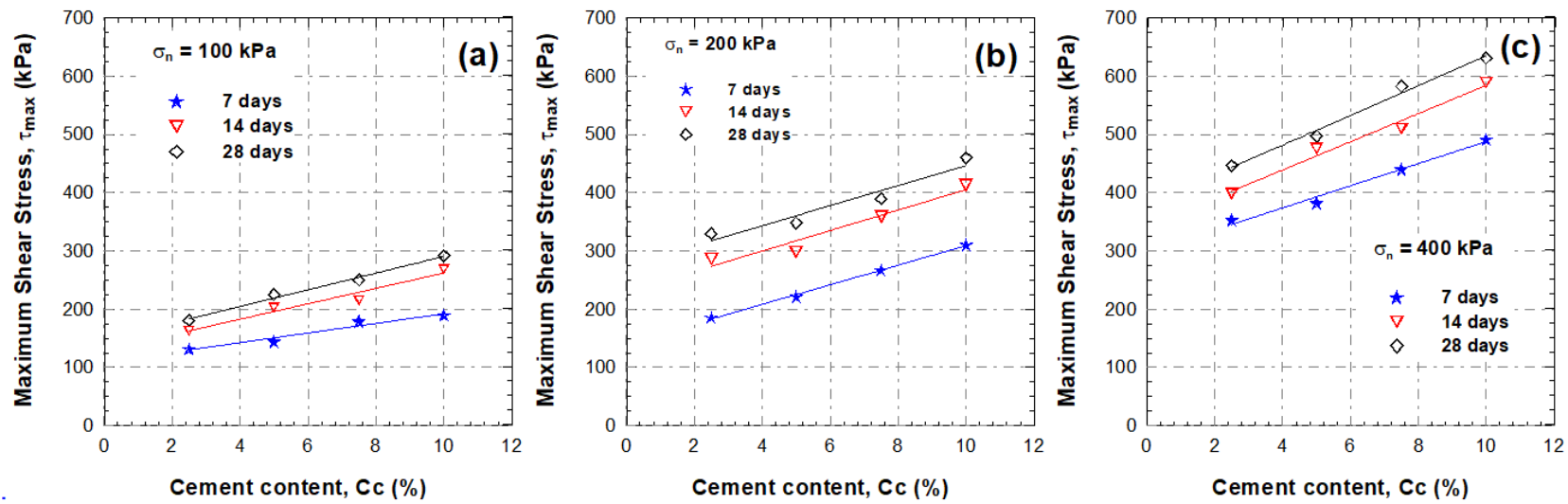

Figure 11: Influence of cure time on the maximum shear strength of cemented sand, (a) Normal stress of $100 \mathrm{kPa}$, (b) Normal stress of 200 $\mathrm{kPa},(\mathrm{c})$ Normal stress of $400 \mathrm{kPa}$,.
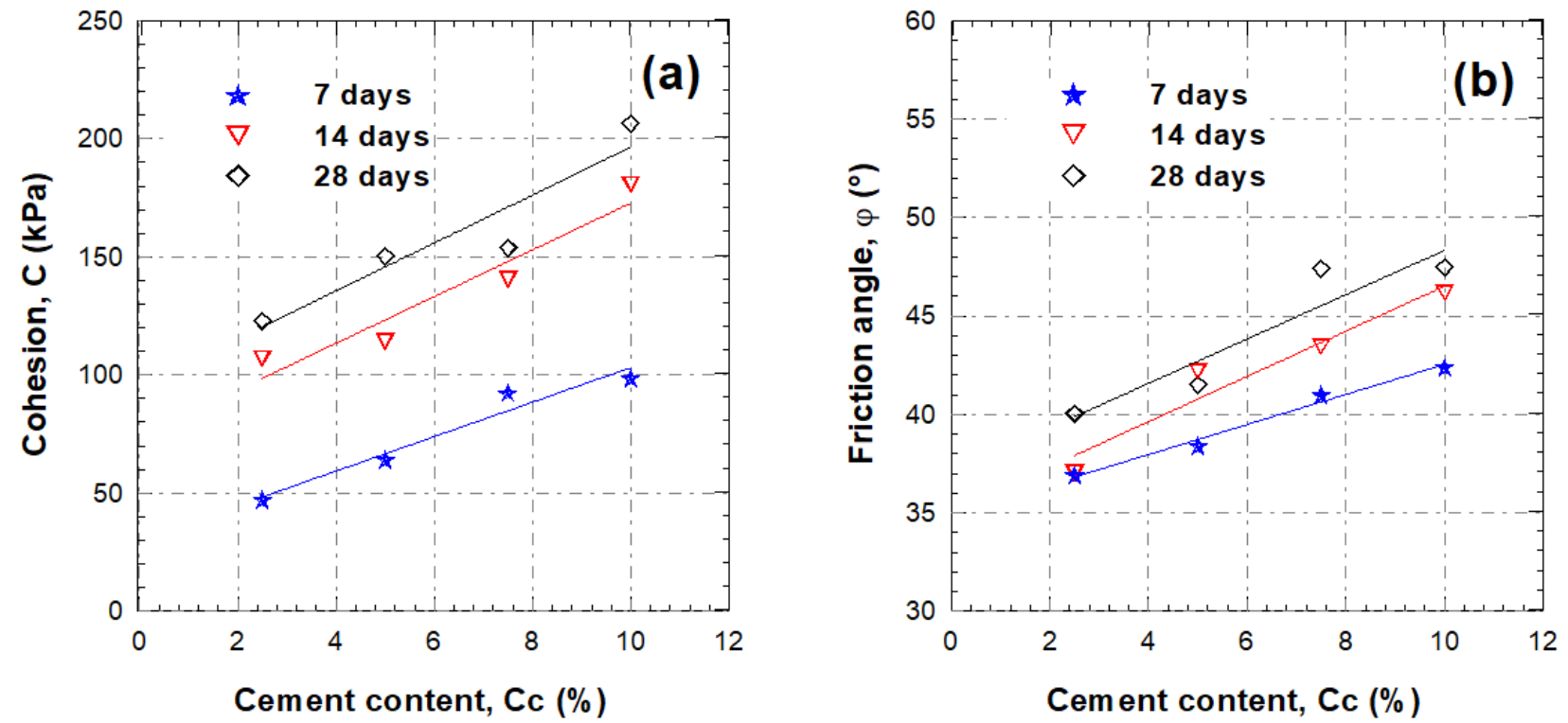

Figure 12: Influence of curing time on the mechanical characteristics of cemented sand.

characterized by a certain efficiency because the cohesion value reaches $94 \mathrm{kPa}$ for a cement content of $2 \%$ (Amini et al 2013), while Chlef sand needs $10 \%$ cement to reach this value for the same relative density ( $80 \%$ and $85 \%)$ and with the same cure time of 7 days. According to the results of Asghari et al, (2003); cohesion reaches a value of 375 $\mathrm{kPa}$ for a cement content of $4.5 \%$.

\section{Conclusions}

In this paper, we present the laboratory results of a series of direct shear tests carried out on unreinforced and cement-reinforced Chlef sand, the reinforced sand samples prepared with cement contents of 2.5, 5, 7.5, 10\% and with different water content $(\omega=3,7$ and $10 \%)$ in order to study the mechanical behavior of a sand-cement mixture and their influence on the mechanical characteristics, that is, maximum shear strength, intercept cohesion and friction angle. All the samples were consolidated and sheared under normal stresses of 100, 200 and $400 \mathrm{kPa}$, which considered constant in all the test steps. The following conclusions were drawn:

- The shear strength and the deformability of cemented reinforced sand under study are strongly affected by water content, cement content and curing time.

- The increase in the water content significantly increases the shear strength of the sand-cement 
Table 4: Summary of our results with those found in the literature.

\begin{tabular}{|c|c|c|c|c|c|c|}
\hline \multirow[b]{2}{*}{ Cc (\%) } & \multicolumn{2}{|l|}{7 days } & \multicolumn{2}{|l|}{14 days } & \multicolumn{2}{|l|}{28 days } \\
\hline & $\mathrm{C}(\mathrm{kPa})$ & $\varphi\left({ }^{\circ}\right)$ & $\mathrm{C}(\mathrm{kPa})$ & $\varphi\left({ }^{\circ}\right)$ & $\mathrm{C}(\mathrm{kPa})$ & $\varphi\left({ }^{\circ}\right)$ \\
\hline 0 & 12.92 & 36.54 & 12.92 & 36.54 & 12.92 & 36.54 \\
\hline 2.5 & 47.29 & 36.9 & 107.04 & 37.03 & 122.97 & 40.05 \\
\hline 5 & 64.31 & 38.41 & 114.22 & 42.19 & 150.38 & 41.51 \\
\hline 7.5 & 92.47 & 41 & 140.58 & 43.46 & 153.72 & 47.4 \\
\hline 10 & 98.76 & 42.39 & 180.69 & 46.17 & 206.54 & 47.47 \\
\hline \multicolumn{3}{|c|}{ Amini et al (2013) } & \multicolumn{2}{|c|}{ Asghari et al (2003) } & \multicolumn{2}{|c|}{ Consoli et al (2009) } \\
\hline Cc (\%) & $\mathrm{C}(\mathrm{kPa})$ & $\varphi\left({ }^{\circ}\right)$ & Cc (\%) & $\mathrm{C}(\mathrm{kPa})$ & Cc (\%) & $\mathrm{C}(\mathrm{kPa})$ \\
\hline 0 & 0 & 38.74 & 0 & 0 & 0 & 0 \\
\hline 1 & 58.15 & 42.28 & 1.5 & 200 & 1 & 19.5 \\
\hline \multirow[t]{3}{*}{2} & 94 & 43.13 & 3 & 250 & 4 & 84 \\
\hline & & & 4.5 & 375 & 7 & 146.5 \\
\hline & & & & & 10 & 328 \\
\hline
\end{tabular}

mixture due to the hydration of the cement, and reduces the deformability of the sand-cement mixtures (by increasing the dilatant character).

- The addition of cement in the sand increases the shear strength considerably; it not only improves the shear strength of the soil, but also provides diversity in the resistance against the deformations imposed loads, which can result in a minimization of expansioncontraction cracks of the specimens.

- Both internal friction angle and intercept cohesion increased when cement was added. The peak friction angle increased in the mixture with $10 \%$ of cement content comparing with samples reinforced with 2.5 cement content; from $34.2^{\circ}$ to $37.4^{\circ}$ for $3 \%$ water content and from $36.8^{\circ}$ to $42.3^{\circ}$ for $10 \%$ water content. It can be concluded that the cement content has a great effect on the shear strength of cemented soil, but in addition to the effect of water content, which decreases immediately due to cement hydration. So, the increase of the curing time makes increasing the shear strength and consequently also increases on the cohesion and the angle of friction because continuous cementing reactions. We must note here that it is recommended to test specimens with greater values of water content to better establish its optimum contribution. Another parameter can affect the mechanical characteristics of cemented soils; curing time has a great effect on the shear strength, and thus, the intercept cohesion and friction angle, where we found that the mechanical characteristics increased with increasing the values of curing time under study.

As recommendations, cemented reinforced sand would be an interesting solution to obtain a synthetic material against the falls of the resistance and to treat well the problem of the instability and the deformability of the sand. In this case, our research is progress with drained and undrained monotonic and triaxial tests and even cyclic tests on cemented sand to confirm the conclusions and observations presented in this study. Another program on fiber reinforced cemented sand and modeling by Flac3D software are in the program of our research.

Acknowledgement: The authors would like to thank the reviewers for their critical review and suggestions for improving the quality of this manuscript. Tests were performed in the Laboratory of Material Sciences and Environment (LsmE) at UHBC University of Chlef. The authors express their gratitude to all who assisted in the preparation of this paper.

\section{References}

[1] Ahnberg, H., S.E. Johanson, H. Pihl and Carlsson T. (2003). Stabilising effects of different binders in some Swedish Soils. Ground Improvement. 7(1): 9-23.

[2] Amini Y, Hamidi A, Asghari E. (2013). Shear strengthdilation characteristics of cemented sand-gravel mixtures. 
International Journal of Geotechnical Engineering, 2014 VOL 8 NO 4.

[3] Aouali, N., Benessalah, I., Arab, A., Ali, B., Abed, M. (2018). Shear Strength Response of Fibre Reinforced Chlef (Algeria) Silty Sand: Laboratory Study. Geotech Geol Eng 2018. Https:// doi.org/10.1007/s10706-018-0641-5

[4] Arab A., (2008). Comportement des sols sous chargement monotone et cyclique. PhD diss., University of Sciences and Technology of Oran, Oran, Algeria

[5] Arab A., (2009). Comportement monotone et cyclique d'un sable limoneux. C. R. Mecanique 337, 621-631

[6] Arab A., Sadek M., Belkhatir M., Shahrour I. (2014). Monotonic preloading Effect on the Liquefaction Resistance of Silty Sand: a Laboratory Study. Arabian Journal for Sciences Engineering. 39:685-694. DOI 10.1007/s13369-013-0700-4

[7] Asghari, E., Toll, D., \& Haeri, S., (2003). Triaxial behaviour of a cemented gravelly sand, Tehran alluvium. Geotechnical and Geological Engineering. 21 (1), 1-28.

[8] ASTM D 3080 (2005). Standard test method for direct shear test of soils under consolidated drained conditions, American Society for Testing and Materials, West Conshohocken, 2005.

[9] Baxter, C. D. P., Sharma, M. S. R., Moran, K., Vaziri, H. And Narayanasamy, $R$, (2011). Use of $A^{-}=0$ as a Failure Criterion for Weakly Cemented Soils. J. Geotech. Geoenviron. Eng., 137, 161-170.

[10] Belkhatir, M.; Schanz T.; Arab A. (2013). Effect of fines content and void ratio on the saturated hydraulic conductivity and undrained shear strength of sand-silt mixtures, Environ. Earth Sci. (2013). doi:10. 1007/s12665-013-2289-z

[11] Benessalah, I., Arab, A., Sadek, M., Bouferra R. (2019). Laboratory study on the compressibility of sand-rubber mixtures under one dimensional consolidation loading conditions. Granular Matter (2019) 21: 7. https://doi. org/10.1007/s10035-018-0860-8

[12] Benessalah, I., Lambert, S., Villard, P., Arab, A. (2018). Effect of dynamics on the Soil-geosynthetic interfaces used in reinforced rockfall embankments. Rock slope stability symposium, Nov 2018, Chambéry, France. Rock slope stability, 2018. <hal-02000349>

[13] Benessalah I. (2017). Comportement des interfaces géosynthétiques sous chargement dynamique due à l'impact. $P h D$ thesis, Faculty of Civil engineering \& Architecture, University of Chlef 2017.

[14] Benessalah I., Arab A., Villard P., Merabet K., Bouferra R. (2016). Shear Strength Response of a Geotextile-Reinforced Chlef Sand: A Laboratory Study. Geotech Geol Eng 2016. 34 (6) : pp 1775-1790. Doi:10.1007/s10706-016-9988-7

[15] Benessalah I., Arab A., Villard P., Sadek M., Kadri A. (2015). Laboratory Study on Shear Strength Behavior of Reinforced Sandy Soil: Effect of Glass-Fibers Content and Other Parameters. Arab J Sci Eng. 2015. 41 (4) : pp 1343-1353. Doi:10.1007/s13369-015-1912-6

[16] Bennert, T., Maher, M., Jafari, F. \& Gucunski, N. (2000). Use of dredged sediments from newark harbor for geotechnical applications. ASTM Special Technical Publication. 1374, 152-164.

[17] Bergado, D. (1996). Soft ground improvement: in lowland and other environments. American Society of Civil Engineers.
[18] Chew, S., Kamruzzaman, A. \& Lee, F. (2004). Physicochemical and engineering behavior of cement treated clays. Journal of geotechnical and geoenvironmental engineering. 130, 696.

[19] Consoli, C. N., Prietto D. M., Ulbrich L. A, (1998). Influence of fiber and cement addition on behavior of sandy soil. Journal of Geotechnical and Geoenvironmental Engineering. ASCE. 124, 1211-1214.

[20] Consoli NC, Viana da Fonseca A, Cruz RC, Heineck KS, (2009). Fundamental parameters for the stiffness and strength control of artificially cemented sand. Journal of Geotechnical Engineering. 135(9):1347e53.

[21] Consoli NC, Cruz RC, Floss MF, (2010). Parameters controlling tensile and compressive strength of artificially cemented sand. Journal of Geotechnical and Geoenvironmental Engineering; 136(5):759e63.

[22] Consoli NC, Cruz RC, Floss MF, (2011). Variables controlling strength of artificially cemented sand: influence of curing time. Journal of Materials in Civil Engineering. 23(5):692e6.

[23] Coop, M. R., \& Atkinson, J. H, (1993). The Mechanics of Cemented Carbonate Sands. Geotechnique , 43 (1), 53-68.

[24] Della N, Arab A, Belkhatir M (2011). A laboratory study of the initial structure and the overconsolidation effects on the undrained monotonic behavior of sandy soil from Chlef region in northern Algeria. Arab J Geosci. 4(5- 6):983-991

[25] Della, N., Belkhatir M., Arab A., Canou J. and Dupla JC. (2014). Undrained Monotonic Response and Instability of MediumDense Sandy Soil. Marine Georesources and Geotechnology. 2014. 33 (6), 487-495. DOI: 10.1080/1064119X.2014.954175

[26] Djafer Henni A., Arab A., Belkhatir M., Hamoudi S.A., Khelafi H. (2011). Undrained behavior of silty sand: effect of the overconsolidation ratio. Arab J Geosci. doi:10.1007/s12517-0110365-9

[27] Dos Santos, A.P.S.; Consoli, N.C.; Heineck, K.S.; Coop,M.R. (2010). High-pressure isotropic compression tests on fibrereinforced cemented sand. J. Geotech. Geoenviron.Eng. 136(6), 885-890

[28] Haeri, S. M., Hamidi, A., Hosseini, S. M., Asghari, E. And Toll, D. $\mathrm{G}$, (2006). Effect of cement type on the mechanical behavior of gravely sand, Geotech. Geol. Eng. J., 24, 335-360.

[29] Hashimoto, H., S. Nishimoto and H. Hayashi, (2009). Investigation of improvement strength variation for the Trencher mixing method. Deep Mixing '09, Okinawa.

[30] Heathcote, K, and Piper R, (1994). Strength of Cement Stabilised Pressed Earth Blocks with Low Cement Contents. J. Proc. Roy. Soc. New South Wales, vol. 127, pp. 33-37.

[31] Hirabayashi, H., H. Taguchi, S. Tokunaga, N. Shinkawa, T. Fujita, H. Inagawa and N. Yasuoka, (2009). Laboratory mixing tests on cement slurry preparation, specimen preparation and curing temperature. Deep Mixing '09, Okinawa.

[32] Huang, J. T., \& Airey, D. W, (1998). Properties of artifically cemented carbonate sand. Journal of Geotechnical and Geoenvironmental Engineering. pp 124 (6), 492-499.

[33] Kido, Y., S. Nishimoto, H. Hayashi and H. Hashimoto, (2009). Effects of curing temperatures on the strength of cementtreated peat. Deep Mixing '09, Okinawa.

[34] Lee MJ, Hong SJ, Choi YM, Lee W, (2010). Evaluation of deformation modulus of cemented sand using CPT and DMT. Engineering Geology. 115(1/2):28e35. 
[35] Maher, M. And Ho, Y, (1993). Behavior of fiber reinforced cemented sand under static and cyclic loads. Geotechnical Testing Journal. 16(3), pp. 330-338.

[36] Marri A. Wanatowski D. and Yu H.S. (2010). Drained behaviour of cemented sand in high pressure triaxial compression tests. Procedia Geomechanics and Geoengineering. 7 (3), 159-174

[37] Mateus Forcelini, Gregório Rigo Garbin, Vítor Pereira Faro, Nilo Cesar Consoli. (2016). Mechanical Behavior of Soil Cement Blends with Osorio Sand. Procedia Engineering. Volume 143, 2016, Pages 75-81

[38] Merabet, K., Benessalah, I., Chemmam, M., Arab, A. (2019). Laboratory study of shear strength response of Chlef natural sand: Effect of saturation. Marine Georesources \& Geotechnology. Online first: 11 May 2019. doi.org/10.1080/106 4119X.2019.1595792

[39] Schnaid, F., Prietto, P., \& Consoli, N, (2001). Characterization of Cemented Sand in Triaxial Compression. Journal of Geotechnical and Geoenvironmental Engineering. 127 (10), 857-868.

[40] Shahnazari H, Rezvani R, (2013). Effective parameters for the breakdown of limestone particles Sands: an experimental study. Engineering Geology. 159: 98-105.

[41] Sharma, M. S. R., Baxter, C. D. P., Hoffmann, W., Moran, K. And Vaziri, H, (2011). Characterization of weakly cemented sands using nonlinear failure envelopes. Int. J. Rock Mech. Min. Sci. 48, 146-151.

[42] Umesha,T.S.,Dinesh,S.V., \& Sivapullaiah, P.V, (2009). Control Of Dispersivity Of Soil Using Lime And Cement. International Journal Of Geology. Issue 1, Vol. 3, pp 9.8-16

[43] Venkatarama Reddy, B. V. And Gupta, A. (2005). Characteristics of soil-cement blocks using highly sandy soils. Materials and Structures. Vol. 38, No. 6, pp. 651-658.

[44] Walker, P. Strength, (1995). Durability and Shrinkage Characteristics of Cement Stabilised Soil Blocks. Cement \& Concrete Composites. 17, 4, pp. 301. 310.

[45] Zillur Rabbi ATM., J. Kuwano, J. Deng , T. Wee Boon, (2011). Effect of curing stress and period on the mechanical properties of cement-mixed sand. Soils And Foundations. Japanese Geotechnical Society. vol. 51, no. 4, 651-661. 